\title{
Thermal-Damage-Free TMR Heads
}

\author{
N. Yoshida, K. Etoh, T. Shintani, K. Meguro, M. Hatatani, and K. Watanabe \\ Central Research Laboratory, Hitachi, Ltd., 2880 Kouzu, Odawara-shi, Kanagawa 256-8510
}

We have developed a way of making TMR heads that are free from thermal damage. We found that during the annealing stage in the write head process the resistance area (RA) product increased and the magnetoresistance ratio (MR) decreased. This degradation depended on the kind of insulator material on both sides of the TMR junction. Because $\mathrm{Al}_{2} \mathrm{O}_{3}$ has a relatively high Gibbs free energy, it suppressed the degradation, and thus oxidation at the sensor edge caused less thermal damage. To prevent thermal damage, we developed a TMR head with a Damascene coil process in the write head. It showed no degradation after the write head process, and, furthermore, had good readback performance.

Key words: TMR head, read head, thermal damage, write head, inductive head, Damascene coil process

$$
\text { サーマルダメージフリーTMR ヘッド }
$$

芳田伸雄・江藤公俊・新谷 拓・目黒賢一・幡谷昌彦・渡邊克朗

（株）日立製作所 中央研究所，神奈川県小田原市国府津 2880（下256-8510）

\section{1. はじめに}

磁気ディスク装置の高記録密度化に伴い，キーデバイス である薄膜磁気ヘッドには，トラック幅やギャップ長など の幾何学寸法の狭小化および高出力化が絶えず求められて いる．近年の薄膜磁気ヘッドは，再生へッドと記録へッド から構成されており, そのうち, 再生へッドにおいては, 磁気抵抗効果センサ膜の膜面内方向にセンス電流を流す CIP(Current into plane)構造素子が用いられてきた。しか しながら, CIP 構造ヘッドで実現できるシールド間距離 (以 下，再生ギャップ長と記す）は約 $60 \mathrm{~nm}$ 程度であり，それ 以下に狭くするためには $\operatorname{CPP}$ (Current perpendicular to plane)構造へッド 1)-7)が必要となる. その代表的なものの 一つが TMR(Tunneling magnetoresistive)ヘッド 1)-4)であ り，障壁層を挟んで設けられた 2 層の磁性層の相対的な磁 化方向に応じてトンネル電流が変化することを利用したも ので，高い出力が得られることが特徵である.

一方，再生へッドとして TMR ヘッドを用いる場合にお いても，記録ヘッドに関しては，上部磁極と下部磁極の間 にコイルが配置されたインダクティブヘッドが用いられ， 一般的には，コイルを絶縁するための有機絶縁体形成の際 に $250 \sim 300^{\circ} \mathrm{C}$ 程度の熱処理が施される. 再生へッドにはこ の熱処理でも劣化を起こさない熱安定性が必要である.

MRAM(Magnetic Random Access Memory)向けに研究開 発されている比較的厚い障壁層を有する TMR 素子につい ては, 熱安定性改善の検討が行われているが 8)9), 薄い障壁 層を有する磁気へッド用の TMR 素子およびその形成プロ セスに関する報告は少ない, そこで，我々は，TMRへッド の記録へッドプロセスまで含めた熱安定性を評価して劣化 の原因について検討を行い, さらに, 記録へッドプロセス を改良することによって, 狭トラック幅においても熱劣化 （以下，サーマルダメージと記す）が殆ど無いTMRヘッ
ドを形成することに成功したので，その結果について報告 する.

\section{TMR ヘッドの特性劣化}

Fig. 1 に, 再生ヘッドとして TMRヘッドを, 記録へッドとして インダクティブヘッドを用いた薄膜磁気ヘッドの構造を示す。基 本的なインダクティブヘッドの構造は，下部磁極，上部磁極と， その間に設けられた記録電流を流すコイルからなっており, コイ ルについては，コイル間及び上部磁極と下部磁極との間で電気的 絶縁を取ることが必要である. 通常, コイル絶縁膜形成プロセス としては，コイル絶縁膜として用いるホトレジストを硬化させる ために $250 \sim 300^{\circ} \mathrm{C}$ 程度の熱処理が用いられ，また，上部磁極お よび下部磁極形成の際にはイオンミリングなどによるトラック幅 形成プロセスが用いられる. インダクティブヘッドプロセスによ る TMRヘッド特性の変化を調ベた結果を Fig. 2 に示す. なお,

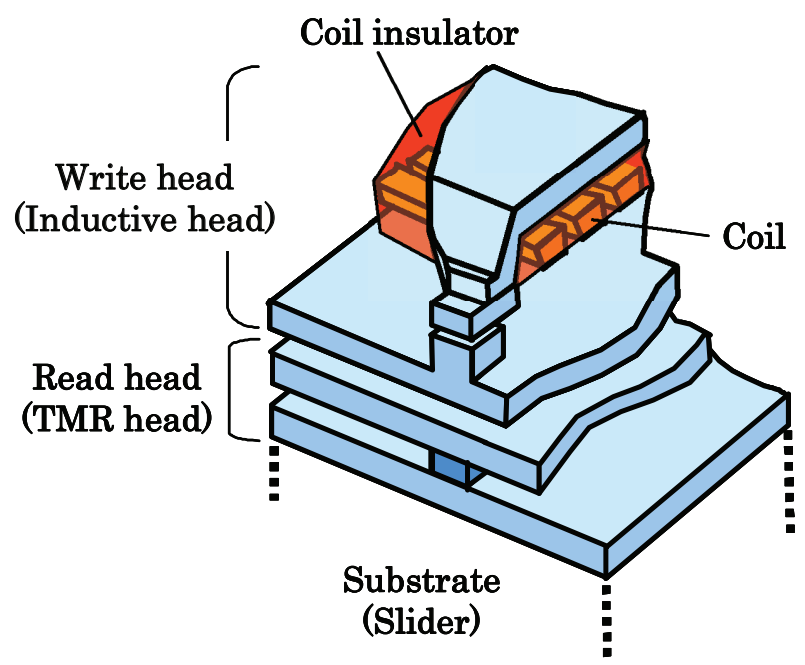

Fig. 1 Schematic of conventional magnetic head with TMR read head. 


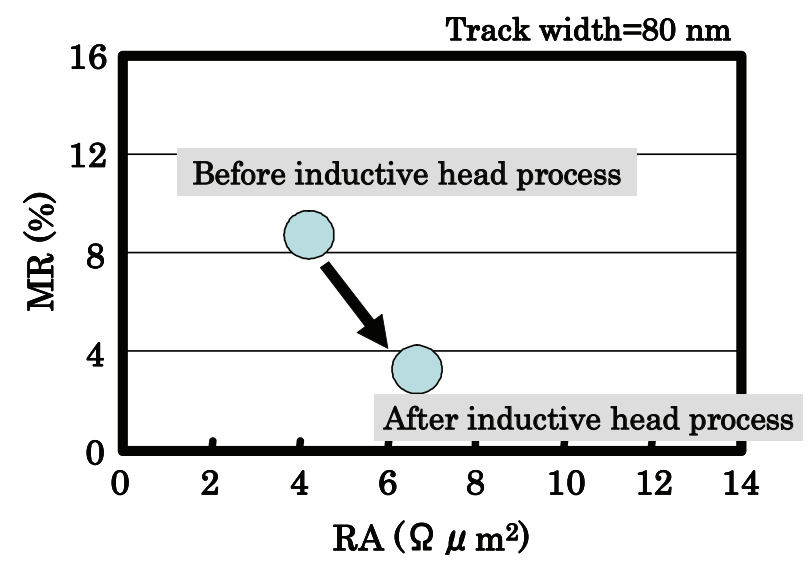

Fig. 2 TMR property degradation after write head process.

TMR ヘッドとしては，センサ膜構成としてシード層/PtMn $14 / \mathrm{CoFe} 1.5 / \mathrm{Ru}$ 0.8/CoFe $2 / \mathrm{Al}-\mathrm{O} \sim 1 / \mathrm{CoFe} 0.5 / \mathrm{NiFe} 4 / \mathrm{Ta} 6$ [nm] を有し，センサ膜画脇には絶縁膜を介して縦バイアス印加層を配 置したアバット構造を有するものである. Fig. 2 は, インダクティ ブヘッドプロセス前後における TMRヘッドの面積抵抗RAと MR 比の関係を示したものであり，インダクティブヘッドプロセス後 において MR 比は約 $1 / 3$ に減少し，RA は約 2 倍に増大している ことが分かる. この著しい特性劣化の原因を追跡したところ，上 部磁極および下部磁極形成時のイオンミリングなどによるダメー ジではなく，コイル絶緑膜形成時の熱処理工程であることが判明 した.つまり，低抵抗で出力の高いTMRヘッドを得るためには， このサーマルダメージ防止が必要であり, 次節 3 においてはTMR ヘッドの構造について，4節においてはインダクティブヘッドの 構造に関して検討した結果を述べる.

\section{TMR ヘッド構造の検討}

TMRヘッドの構造は, センサ膜を構成する TMR 膜の中には障 壁層となる絶縁膜を配置し, エッチングにより所望の寸法に TMR センサを形成した後には，センス電流を TMR センサの夕に流す ために TMRセンサ周囲に絶緑膜（以下，ギャッブ絶縁膜と記す） が配置される.このようにセンサ膜周囲に絶縁膜が隣接する構造 は TMR ヘッドに特異なものであるため, ギャッブ絶縁膜とサー マルダメージの関係について検討した. 検討を行った素子は，Fig. 3(a)に示すような素子構造で，TMRセンササイズは $0.6 \mu \mathrm{m} \times 0.6$ $\mu \mathrm{m}$, ギャッブ絶縁膜の材料としては, $\mathrm{Al}_{2} \mathrm{O}_{3}$ 及び $\mathrm{SiO}_{2}$ を用いた.

Fig. 3 (b) はコイル絶緑膜形成プロセスの熱処理前後における MR 比および RA の変化を示したものであり, MR 比および RA 共に 熱処理前の值で規格化してある. ギャッブ絶縁膜が $\mathrm{Al}_{2} \mathrm{O}_{3}$ または $\mathrm{SiO}_{2}$ であっても, 熱処理後では RA が増大して MR 比が減少して いるが, $\mathrm{SiO}_{2}$ と比べて $\mathrm{Al}_{2} \mathrm{O}_{3}$ の方がこれらの変化が小さいことが 分かる.つまり，サーマルダメージはギャップ絶縁膜の材料に大 きく依存している.

我々は，このサーマルダメージが TMR センサ端部における現 象であると考え, Fig. 4 に示寸モデルを考えた. このモデルは, ギ ヤップ絶縁膜を構成する酸化膜中の酸素が, 熱処理によって拡散

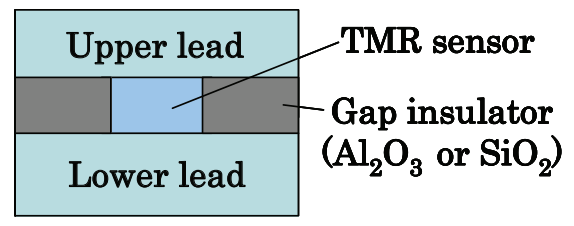

(a)

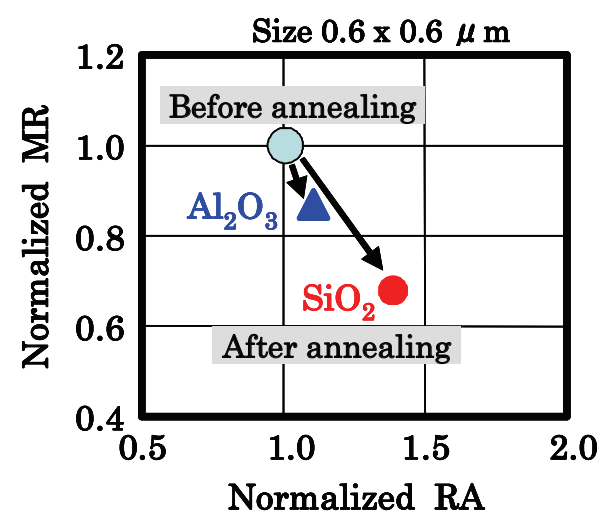

(b)

Fig. 3 Investigation into thermal damage to TMR head structure. (a) Schematic of test device structure with different gap insulators. (b) Change to TMR property materials by annealing damage.

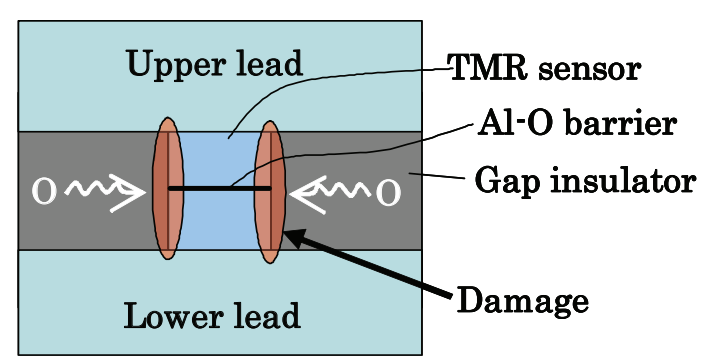

Fig. 4 Model of thermal damage at TMR sensor edge.

して, TMRセンサ端部において TMR膜を構成する材料と反忘し， RA の増大や MR 比の低下をもたらすというものである. ギャッ フ絶縁膜である $\mathrm{Al}_{2} \mathrm{O}_{3}$ と $\mathrm{SiO}_{2}$ の化学的な安定性を標淮生成エネル ギ一を尺度に比較してみると， $\mathrm{Al}_{2} \mathrm{O}_{3}$ は- $1055 \mathrm{~kJ} / \mathrm{mol}^{10)}, \mathrm{SiO}_{2}$ は- $851 \mathrm{~kJ} / \mathrm{mol}^{10)}$ であり, $\mathrm{Al}_{2} \mathrm{O}_{3}$ の方がより安定であるということ ができ，材料による違いを説明することができる.

このような TMR センサ端部での酸化によるダメージを仮定す ると，トラック幅によりサーマルダメージの劣化に違いが生じる ことが考えられる. Fig. 5 は, ギャッブ絶縁膜が $\mathrm{Al}_{2} \mathrm{O}_{3}$ である場合 のサーマルダメージのトラック幅依存性である. 評価は, Fig. 5(a) に示すような TMRヘッド構造を用い, TMRセンササイズはトラ ック幅 $80 \sim 145 \mathrm{~nm}$ 及び素子高さ $1.5 \mu \mathrm{m}$, 熱処理前後の MR 特性 を測定し，熱処理前の值で規格化することにより行った. Fig. 5(b) 


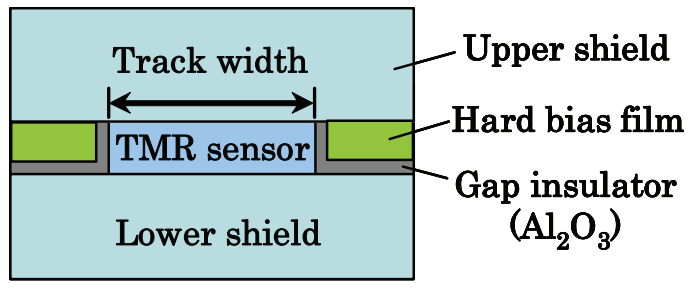

(a)

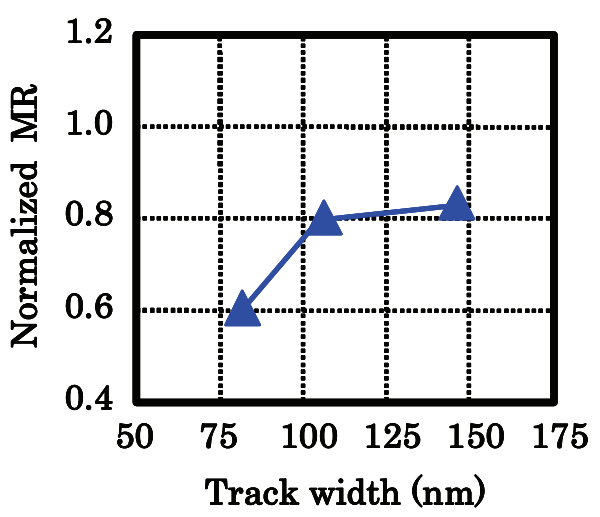

(b)

Fig. 5 Investigation into thermal damage to TMR head. (a) Schematic TMR head structure. (b) Dependence of thermal damage on track width.

に示すようにトラック幅 $145 \mathrm{~nm}$ での熱処理後における MR 比は, 熱処理前の約 82\%を維持しているが，トラック幅が狭くなると共 にMR比は劣化し, トラック幅 $80 \mathrm{~nm}$ では約 $60 \%$ にまで劣化する. この結果から，トラック幅が狭いほど劣化が大きいことが分かる. Fig. 4 のモデルでは, 酸化によるダメージを受ける層の厚さは一定 と考えることができるので，狭いトラック幅ではそのダメージ層 の相対的割合が大きくなり，その結果，サーマルダメージによる 劣化はより顕著になるものと説明できる.

以上の結果より, TMR ヘッドのサーマルダメージは, TMR セ ンサ端部における酸化の進行と推定することができる. 実際にセ ンサ膜のどの層がどれだけ酸化しているかは不明であるが，これ までの RA が増大及び MR 比が劣化するという結果から磁性層端 部や磁生層/障壁層界面の端部における酸化の影響が大きいと考え ている．つまり，酸化によって端部の実効的障壁膜厚が大きくな ることでRAが増大寸ることと，磁性層の分極率低下による MR 比の劣化が同時に発生することがサーマルダメージの原因と考え ている. また，サーマルダメージは，化学的に安定なギャッブ絶 縁膜を用いることによって低减できると考えられる. 今後, 更に トラック幅が狭くなるとサーマルダメージがより顕著になること が予想され，ギャッブ絶縁膜の材料や形成方法の改良が必要にな るものと考えられる.

\section{4. インダクティブヘッドに関する検討}

前節において, TMRヘッドの構造，具体的にはギャップ絶縁 (a)

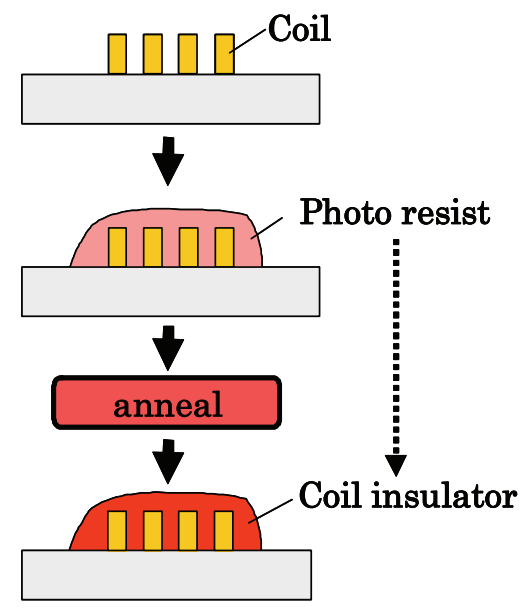

Fig. 6 Conventional coil process.

(a)

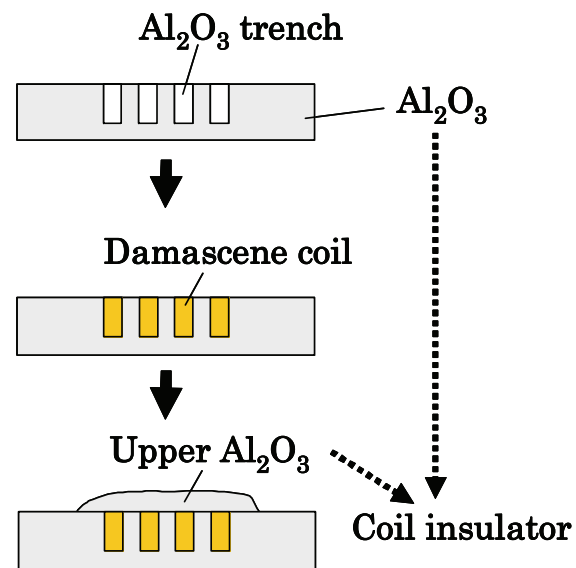

Fig. 7 Damascene coil process.

膜を検討した結果, 化学的に安定な材料をギャッブ絶縁膜に用い ることにより, サーマルダメージを低減できることが分かった. しかし, Fig. 5 (b)の結果に示寸ように, 化学的に安定な $\mathrm{Al}_{2} \mathrm{O}_{3}$ ギ ヤップ絶縁膜を用いても, 狭いトラック幅においてはサーマルダ メージの抑止効果が十分ではない.

そこで我々はインダクティブヘッドの作製プロセスにおいて, RA の増加及び MR の劣化の原因となる熱処理工程の影響を低减 する試みを検討した。 具体的には，コイル絶縁膜の熱処理そのも のをなくす為, ダマシンプロセスを用いてコイル絶縁膜およびコ イルを形成し，ヘッド作製を行った. Fig. 6 およびFig. 7 におい て, 従来のコイル形成プロセスと我々が開発したダマシンコイル 形成プロセスを比較する. 従来のコイル形成プロセス Fig. 6 は, (a) コイルを形成し, (b)フォトレジストでコイルを覆った後, 熱処理 を行い, (c)コイル絶縁膜を形成するのに対し, ダマシンコイル形 成プロセス Fig. 7 は, (a) $\mathrm{Al}_{2} \mathrm{O}_{3}$ 膜にコイル溝を掘り込んでトレン チを形成し，(b)トレンチ内にダマシンプロセスを用いてコイルを 埋め込み, (c)コイル上部に $\mathrm{Al}_{2} \mathrm{O}_{3}$ 膜を成膜し, コイルを囲む $\mathrm{Al}_{2} \mathrm{O}_{3}$ 膜がコイル絶縁膜を形成する. Fig. 8 はダマシンコイル形成プロセ スを用いて形成したインダクティブヘッドを搭載した TMRヘッ 


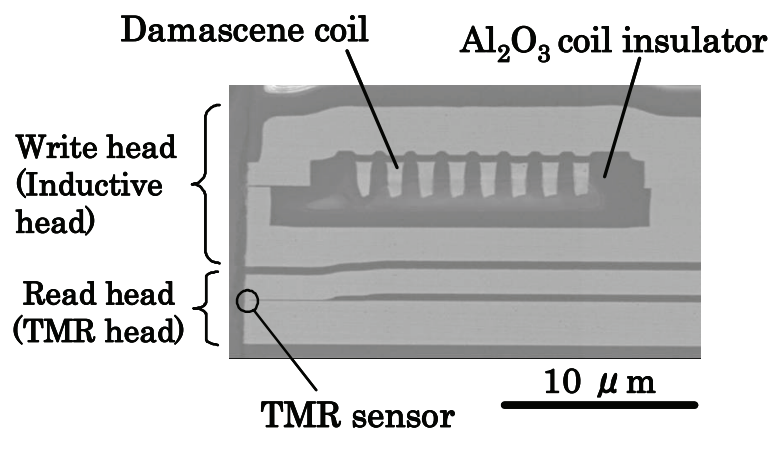

Fig. 8 Cross-sectional SEM image of TMR head with Damascene coil write head.

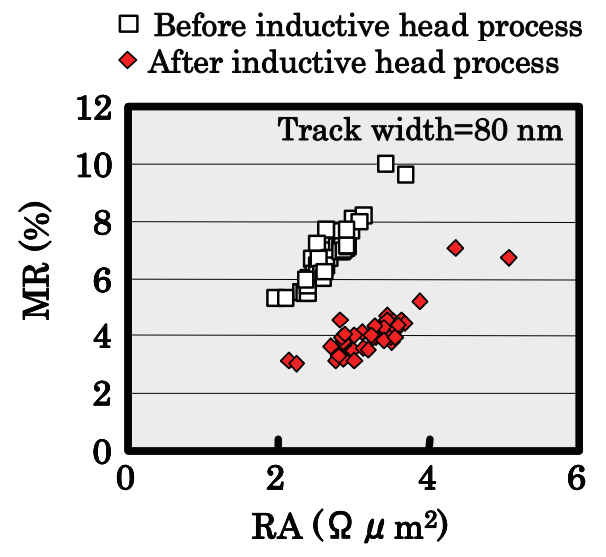

Fig. 9 TMR properties before and after write head process with conventional coil.

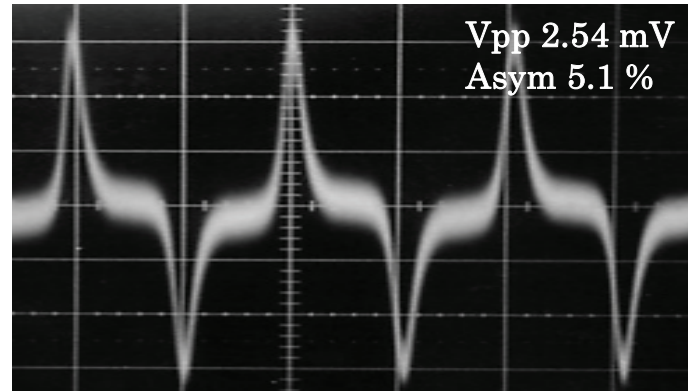

Fig. 11 Readback waveform of TMR head with Damascene coil write head.

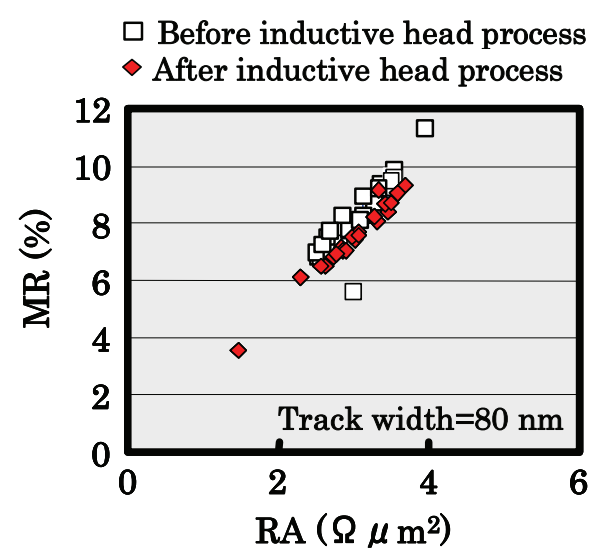

Fig. 10 TMR properties before and after write head process with Damascene coil.
ドの SEM 像である.コイルが $\mathrm{Al}_{2} \mathrm{O}_{3}$ コイル絶縁膜に埋め込まれて いることが観察できる.ダマシンコイルはPlaner-Pole-Tip (以下， PPT と記す) ヘッド11) 構造と組み合わせて形成した. PPTヘッド の特徴としては，上部磁気コアを分割形成し，記録トラック幅を 規定する磁気コアを平坦面上に形成寸るため，狭トラック幅形成 及び、法高精度化が両立可能な構造である.

従来コイル形成プロセスを用いた場合のTMRヘッドのMR-RA 特性を Fig. 9 に, ダマシンコイル形成プロセスを用いた場合の MR-RA 特性を Fig. 10 に示寸. なお，TMRへッドのギャッフ絶 縁膜は $\mathrm{Al}_{2} \mathrm{O}_{3}$ を用い，トラック幅は 80nm である. Fig. 9 の従来 コイル形成プロセスの場合には，インダクティブヘッド形成後に 大幅な特性劣化が認められるが，一方，Fig. 10 のダマシンコイル 形成プロセスの場合には，ほとんど MR，RA ともに変化が無く， 特性が劣化していないことが分かる。つまり，ダマシンコイル形 成プロセスを採用することで TMR ヘッドのサーマルダメージを 無くすことができる.

ダマシンコイル形成プロセスを適用して試作した TMR ヘッド の記録再生波形を Fig. 11 に示寸．TMRヘッドの再生トラック幅 は $80 \mathrm{~nm}$ ，再生ギャップ長は $57 \mathrm{~nm}$ であり，インダクティブヘッ
ドの記録トラック幅は $135 \mathrm{~nm}$ ，記録ギャップ長は $74 \mathrm{~nm}$ である. 記録媒体は面内記録媒体である. 再生波形はVpp: $2.54 \mathrm{mV}$ と TMR センサ特性から考えると良好な值であり, 再生波形の非対称性 (Asym)も5.1\%と小さく良好であった. 以上のように，熱処理を 行わないインダクティブヘッドプロセスを採用することにより， TMRヘッドにサーマルダメージを与えることなく, 良好な記録再 生特性を有寸る TMRヘッドが得られることが確認できた。

\section{5. まとめ}

TMR ヘッドにおけるサーマルダメージを防止するため, TMR ヘッドの構造, 及びインダクティブヘッドの構造につ いて検討を行い，以下の結論を得た。

（1） TMR ヘッドの MR 特性のサーマルダメージは，ギヤ ップ絶縁膜を化学的に安定な材料を用いることによ り低減できる。

(2) このサーマルダメージはギャップ絶縁膜から酸素の拡散な ぞによってTMR 膜端部酒夋化するためと考えられる。

（3）インダクティブヘッドとして, コイル絶縁膜の熱処理 を必要としないダマシンコイルプロセスを採用する 
ことにより，狭いトラック幅においてもインダクティ ブヘッドプロセス後で MR 特性の劣化がないヘッド を得ることができた。

\section{References}

1) S. Araki, K. Sato, T. Kagami, S. Saruki, T. Uesugi, N. Kasahara, T. Kuwashima, N. Ohta, J. Sun, K. Nagai, S. Li, N. Hachisuka, H. Hatate, T. Kagotani, N. Takahashi, K. Ueda, and M. Matsuzaki, IEEE Trans. Magn., 38, 72 (2002).

2) T. Kuwashima, K. Fukuda, H. Kiyono, K. Sato, T. Kagami, S. Saruki, T. Uesugi, N. Kasahara, N. Ohta, K. Nagai, N. Hachisuka, N. Takahashi, M. Naoe, S. Miura, K. Barada, T. Kanaya, K. Inage, and A. Kobayashi, IEEE Trans. Magn., 40, 176 (2004)

3) T. Kagami, T. Kuwashima, S. Miura, T. Uesugi, K. Brada, N. Ohta, N. Kasahara, H. Sakiyono, S. Saruki, K. Inage, N. Takahashi, and K. Terunuma, IEEE Trans. Magn., 42, 93 (2006).

4) S. Mao, Y. Chen, F. Liu, X. Chen, B. Xu, P. Ru, M. Patwari, H. Xi, C. Chang, B. Miller, D. Menard, B. Pant, J. Loven, K. Duxstad, S. Li, Z. Zhang, A. Johnston, R. Lamberton, M.
Gubbins, T. McLaughlin, J. Gadbois, J. Ding, B. Cross, S. Xue, and P. Ryan, IEEE Trans. Magn., 42, 97 (2006).

5) A. Matsuzono, S. Terada, H. Ono, A. Furukawa, T. Sone, S. Sasaki, Y. Kakihara, T. Takeda, N. Chiyokubo, and H. Matsuki, J. Appl. Phys., 91, 7267 (2002).

6) A. Tanaka, Y. Seyama, A. Jogo, H. Oshima, R. Kondo, H. Kishi, C. Kamata, Y. Shimazu, S. Eguchi, and K.Saitoh, IEEE Trans. Magn., 40, 203 (2004).

7) K. Nakamoto, H. Hoshiya, H. Katada, T. Okada, M. Hatatani, K. Hoshino, N. Yoshida, I. Nunokawa, K. Etoh, and K. Watanabe, IEEE Trans. Magn.,41, 2914 (2005).

8) T. Ochiai, N. Tezuka, K. Inomata, S. Sugimoto, and Y. Saito, J. Magn. Soc. Jap., 27, 307 (2003).

9) S. V. Pietambaram, J. Janesky, R. W. Dave, J. J. Sun, G. Steiner, and J. M. Slaughter, IEEE Trans. Magn., 40, 2619(2004).

10) A. Yazawa, Refinement of Nonferrous Metal (The Japan Institute of Metals), 315 (1979).

11) N.Yoshida, I. Oodake, K. Kudou, M. Fuyama, A. Taniyama, S. Ohtomo, and Y. Maruyama, Digest of the $26^{\text {th }}$ Annual Conference on Magnetics of Japan, 19aB-6 (2002)

2007 年 8 月 29 日受理, 2007 年 11 月 13 日採録 